\title{
TRABALHO, QUALIFICAÇÃO E A CONSTRUÇÃO SOCIAL DE IDENTIDADES PROFISSIONAIS NAS ORGANIZAÇÕES PÚBLICAS DE SAÚDE
}

\author{
WORK, QUALIFICATION AND THE SOCIAL CONSTRUCTION OF PROFESSIONAL IDENTITIES IN \\ PUBLIC HEALTH ORGANIZATIONS
}

Monica Vieira 1

Resumo Este texto é parte de uma pesquisa acerca da relação entre o trabalhador de nível médio e seu trabalho nas organizações públicas de saúde, que teve como propósito repensar as atuais propostas de gestão do trabalho em saúde. Busca-se compreender as repercussões das mudanças contemporâneas no mundo do trabalho sobre o trabalho dos agentes administrativos, um grupo profissional quantitativamente importante dos serviços de saúde. A análise toma como referencial teórico uma vertente da sociologia do trabalho, denominada por Dubar sociologia dos grupos profissionais, que se situa entre uma sociologia do trabalho tradicional, muito centrada na questão salarial, e uma nova sociologia da organização, menos fechada nas análises dos modos de gestão internos. O trabalho de campo acerca das trajetórias profissionais de 18 trabalhadores administrativos foi realizado em duas unidades públicas de saúde. Constatou-se, entre eles, uma grande diversificação de formas de emprego, percursos profissionais e dinâmicas de identidade. Evidenciou-se, assim, que a compreensão da construção dos modos de ser trabalhador deve considerar múltiplas variáveis: formação profissional, vínculo empregatício, setor de atuação profissional, tempo de atuação na área e formas de organização do trabalho.

Palavras-chave trabalho; qualificação; identidade profissional.
Abstract This text is part of a survey carried out regarding the relationship between midtier workers and their work in public health organizations, which was aimed at rethinking the current health work management proposals. The goal was to understand the impact the current changes made in the labor world had on administrative agents, a professional health service group that is important from the quantitative viewpoint. The analysis' theoretical point of reference is a line in labor sociology which Dubar denominates as professional group sociology and is situated between traditional labor sociology, very centered on the salary issue, and a new organizational sociology that focuses less intensely on analyzing internal modes of management. The field work, which involved detailing the professional track records of 18 administrative workers, was carried out in two public health units. It was noticed, among them, that there is a great diversification in the forms of employment, professional backgrounds, and identity dynamics. It was clear, therefore, that multiple variables must be taken into account to understand how worker modes are built: professional qualifications, job ties, sector of professional performance, the amount of time the person has been in the area, and how the work is organized.

Keywords labor; qualification; professional identity. 


\section{Introdução}

O capitalismo contemporâneo, marcado por um processo de degradação dos eixos que se constituíam nos pilares da sociedade salarial, coloca em xeque modos de socialização e formas de integração com base no trabalho, revertendo identidades, filiações e formas de solidariedade (Castel, 1998). Nesse cenário, o trabalho assalariado caracteriza-se por crescentes diferenciações internas, pela segmentação dos empregos e expansão dos serviços, o que suscita uma individualização dos comportamentos no trabalho e uma ruptura da unidade de interesse dos trabalhadores, tendendo ao desaparecimento da consciência de classe.

Uma vez que o trabalho assalariado não pode mais oferecer o eixo em torno do qual é possível fixar identidades e projetos de vida, questiona-se a sua relevância como suporte de inserção na estrutura social, central na construção das identidades. Um dos reflexos do processo de transformação no mundo do trabalho pode ser associado a uma revisão de valores, que nos leva a buscar outra cena de ligação e profundidade, que não o trabalho (Sennet, 2000).

Para Offe (1994), o setor terciário da economia2, por sua lógica e racionalidade próprias - margem mais ampla de atuação, indeterminação de atividades, comunicação e qualificação maiores -, parece mais protegido do processo de degradação do trabalho. Esse autor sinaliza que as funções sociais, que devem ser desempenhadas nas atividades em serviços, baseiam-se na idéia de que são orientadas para a coletividade. O trabalho em serviços possui um forte apelo social capaz de aproximar o mundo do trabalho ao da existência. Já segundo Antunes (2000), as mutações tecnológicas e as mudanças nas formas de gestão também vêm afetando o setor de serviços que, cada vez mais, se submete à racionalidade do capital. Ainda que as mutações do trabalho afetem as relações produtivas nos diversos níveis da economia, destaca a importância de recuperar a idéia do trabalho como fonte de realização.

Considerando tais questões, discutem-se neste artigo os resultados baseados em parte de recente investigação acerca da trajetória profissional de trabalhadores administrativos, no sentido de compreender em que medida as transformações mais amplas relacionadas ao trabalho afetam esses trabalhadores inseridos nos serviços públicos de saúde do país.

Dessa forma, o artigo foi desenvolvido partindo-se dos estudos acerca da relação trabalho e qualificação no capitalismo contemporâneo, tendo como eixo de análise as noções de reconhecimento social e de identidades profissionais. 


\section{Trabalho e qualificação: uma relação que orienta a compreensão de trabalhador}

A compreensão do conceito de qualificação impõe uma reflexão sobre o trabalho, entendido como atividade sobre a qual a qualificação é exercida. A noção de qualificação encontra-se, originalmente, associada a um contexto histórico e social do trabalho em que as exigências profissionais limitavamse à posse de determinados conhecimentos, voltados para a execução de um trabalho prescrito. Nesse contexto, o tempo de formação configurava-se como o melhor meio para a aquisição desses conhecimentos. A gestão dos empregos fundava-se sobre o diploma, padrão de medida que dava conta de um saber explícito e formal.

No cenário atual, os estudos sobre a qualificação parecem conformar um campo estratégico em um momento em que a intensa transformação tecnológica não altera apenas a natureza dos instrumentos de trabalho, mas, sobretudo, as representações simbólicas que ordenam e reproduzem as relações sociais no mundo do trabalho.

Dessa forma, considera-se, neste artigo, a visão relativista da qualificação ${ }^{3}$, que a entende como uma conceituação histórico-concreta que decorre da relação entre capital e trabalho e de fatores socioculturais que influenciam o julgamento e a classificação que a sociedade faz sobre os indivíduos (Tartuce, 2002).

Essa visão compreende a qualificação como uma construção social. Os trabalhadores são considerados qualificados devido à existência de regras deliberadas de restrição à ocupação, coletivamente produzidas, partilhadas e barganhadas - e não necessariamente em decorrência da natureza mesma da ocupação desempenhada (Castro, 1994). Essa concepção acolhe enfoques diferenciados no que se refere à possibilidade de relação entre a habilitação técnica do trabalhador e a sua condição de qualificado.

Partindo do entendimento de qualificação como relação social, o nexo entre trabalho e qualificação deve ser buscado na própria trama das relações técnicas e sociais presentes nos processos de trabalho, nas relações políticas entre saberes e poderes no interior das organizações. Nessas relações encontram-se refletidas as experiências que os trabalhadores trazem e com as quais barganham sua inserção nos sistemas de classificação que organizam as relações no campo profissional (Castro, 1994). Esse entendimento situa a noção de qualificação como uma instância relevante na construção das barreiras que delimitam o campo de reconhecimento de sujeitos, fixando, assim, parâmetros para a construção de formas de identidade.

Pensada do ponto de vista sociológico, a qualificação do trabalho é uma relação social complexa que varia, portanto, conforme a época e não apenas em função de aspectos técnicos e de organização do trabalho. Segundo 
Tartuce (2002), a questão da qualificação transforma-se, principalmente, em função de fatores morais e políticos presentes no julgamento que a sociedade faz sobre a qualidade dos trabalhos necessários à sua reprodução.

No contexto atual, a noção da qualificação é revista, abrindo-se questionamentos que colocam ênfase em novos requisitos para os trabalhadores, que devem responder à imprevisibilidade. Dessa forma, o saber construído na situação de trabalho, o conhecimento tácito, passa a ser mais valorizado pela produção flexível, que, explicitamente, convoca os trabalhadores à participação e ao envolvimento. Essas questões emergem com vigor nos debates da sociologia do trabalho, já que "a ênfase na polivalência, entendida como um conjunto de capacidades que possam enfrentar a complexidade e a imprevisibilidade do novo modo de produzir, significa a passagem do conceito de qualificação para o de competência" (Tartuce, 2002, p. 30).

As conseqüências dessas mutações chegam à organização do trabalho, pois se passa a exigir trabalhadores capazes de atuar em uma pluralidade de situações de trabalho. A relação do trabalhador com seu trabalho é afetada, já que, de forma crescente, se produz mais em menos tempo e com um número cada vez mais reduzido de trabalhadores. Essas mudanças na organização do trabalho, com a valorização de trabalhadores mais qualificados, sinalizam o surgimento da noção de competência4.

Os anos 90 foram marcados por uma nova relação com a competência, com o surgimento da noção de empregabilidade. Não era mais a escola nem a empresa que produziam as competências para os indivíduos se inserirem no mercado, obter um salário e serem reconhecidos. O indivíduo mesmo passa a ser responsável pela aquisição de suas competências. Pergunta-se até que ponto tais exigências demandam maior participação de trabalhadores, valorizam novos perfis profissionais e 'recaracterizam' a organização do trabalho, gerando uma maior qualificação dos trabalhadores.

Assim, a noção de competência supõe um indivíduo racional e autônomo, que monitora seu tempo de formação e de trabalho segundo uma lógica empreendedora de maximização de si. Esse modelo tensiona a construção da identidade coletiva no trabalho, entendida como um processo de criação institucional, que envolve a elaboração e a negociação de regras, de normas e de repertórios comuns. Pode-se dizer que a crise do emprego e do mercado de trabalho é acompanhada de uma crise do trabalho, que aponta para um renovado interesse pela questão das trajetórias e identidades profissionais.

\section{Processos de profissionalização, reconhecimento social e construção de identidades}

O contexto de transformações no processo produtivo parece influenciar a conformação das trajetórias ocupacionais, que adquiriram para a sociologia 
do trabalho um novo interesse. A partir do entendimento da relevância do trabalho como "suporte privilegiado de inscrição na estrutura social", Castel (1998, p. 601) destaca as conseqüências do recente processo de individualização na construção das identidades profissionais.

No cenário contemporâneo, extingue-se a sensação de segurança advinda dos padrões regulares e das expectativas conhecidas de uma vida em comunidade. Os indivíduos encontram-se numa disputa permanente pelo reconhecimento social escasso que emana, principalmente, de práticas sociais que se estruturam em contextos organizacionais.

A questão própria do sentido do trabalho relaciona-se com a produção de identidade, já que as identidades profissionais são as formas socialmente construídas pelos indivíduos de se reconhecerem uns aos outros no campo do trabalho e do emprego. O trabalho aparece, assim, como importante para o reconhecimento de si, como um espaço de conversas, um campo de problemas, de incertezas e de múltiplas implicações.

A temática das identidades profissionais está no centro de uma sociologia que busca analisar as dinâmicas de reconhecimento social das atividades de trabalho, pois o trabalho remunerado e reconhecido constitui um aspecto vital da época atual. Essa questão encontra-se, então, inscrita nos debates sobre o futuro do trabalho, que ultrapassa as organizações e o Estado, mas afeta todos os indivíduos confrontados pelos constrangimentos e pelas escolhas da vida, cada vez mais difíceis, aleatórias e incertas (Dubar e Tripier, 1998).

A complexidade das questões atuais relativas ao trabalho acaba por expor a limitação da concepção anglo-saxã 5 de profissão, que não contempla os diversos trabalhadores inseridos nas organizações, em diferentes níveis hierárquicos, nem os que se encontram desempregados. Tal concepção, considerando que as profissões são típicas das sociedades modernas, busca desvendá-las a partir de uma área temática própria - a sociologia das profissões -, que surge com a tarefa de qualificar o trabalho profissional de modo a diferenciá-lo das demais ocupações 6 .

Segundo a literatura da área, as profissões crescem mediante a apropriação de uma série de condições ou estágios que acabam sendo reconhecidos como itens imprescindíveis ao processo de profissionalização. Parece relevante, ainda, a existência de uma orientação para a coletividade, ou ideal de trabalho, que define os padrões profissionais exigidos e a correta conduta a ser traçada no cotidiano de trabalho7. A profissão torna-se reconhecida, portanto, a partir do momento em que possui um corpo de conhecimento próprio, adquirido com o treinamento formal, tendo sua prática regida por regras sistematizadas.

Em outros termos, quanto mais formalizada for a base cognitiva, mais a linguagem e o conhecimento carregam uma 'capa de cientificidade'. O profissional, munido da legitimidade de um conhecimento específico, sente- 
se valorizado e resguardado na sua autoridade, o que lhe garante um status vinculado ao saber.

Segundo Freidson (1978), foi ao longo do século XIX que ocorreu uma separação entre ofício - identificado como ação técnica que não envolve necessariamente uma dimensão científica própria - e profissão, que possui requisitos científicos e éticos definidos. Além desses requisitos, o autor destaca que, quanto mais nobre for a posição ocupada por uma profissão, maior o investimento de tempo e energia voltado para a formação, mais rigorosa a seleção de aprendizes e maior o compromisso com a ocupação.

Larson 8 constata em seus estudos que o nível de profissionalização atingido por uma profissão depende de aspectos que a favorecem. Destaca que, quanto mais uma atividade for considerada universal e menos acessível aos leigos, mais detém meios para que a profissão galgue espaços considerados nobres, assim como, para o mesmo fim, quanto mais 'esotérico' ou científico for o conhecimento, melhor.

Mais uma vez recorreu-se aos estudos de Dubar e Tripier (1998)9 , para os quais a sociologia das profissões possui um triplo objeto: a organização social das atividades de trabalho, o significado subjetivo dessas atividades e os modos de estruturação do mercado de trabalho. Ela não recupera toda a sociologia do trabalho nem toda a sociologia das organizações e envolve também a sociologia da educação. As relações entre a organização e a profissão são essenciais tanto no que se refere ao trabalho como à carreira. Essas relações se tornam um objeto específico da sociologia francesa, que começa a acumular estudos importantes e convergentes. Situam-se entre uma sociologia do trabalho tradicional, muito centrada na questão salarial, e uma nova sociologia da organização, menos fechada nas análises dos modos de gestão internos, contribuindo para os debates da sociologia dos grupos profissionais.

Considerando-se as análises de Dubar e Tripier (1998) pertinentes para a compreensão do grupo ocupacional estudado neste artigo, podem-se sintetizar suas reflexões apontando que, em primeiro lugar, não existe profissão separada - para compreender um grupo profissional, o sociólogo deve recolocá-lo no sistema profissional ao qual pertence, ou seja, seus problemas de fronteiras com outros, as lutas de classificação das políticas de emprego. Em segundo, não existe profissão unificada, mas sim segmentos profissionais mais ou menos identificáveis, organizados. Esse também é o caso dos assalariados, nos quais o status do emprego, a duração do trabalho e as formas de remuneração constituem fatores de segmentação. Não existe profissão estável, o que há são processos de estruturação e desestruturação profissionais, em que os ritmos históricos, as formas culturais e as configurações políticas são muito variáveis. Não existe profissão objetiva, apenas relações dinâmicas entre as instituições formadoras, de trabalho, de gestão, 
e trajetórias individuais no seio das quais se constroem (ou destroem) as identidades profissionais, sociais e pessoais. Por fim, segundo os autores, não apenas os fatos profissionais influenciam os processos de construção de identidades, mas também as formas típicas de trajetórias individuais e de mundos sociais, os sistemas de crenças e de práticas, o habitus e os projetos de vida.

Nesse sentido, é necessário levar em conta os traços de subjetividade para a compreensão dos processos coletivos, na tentativa de romper com a exclusão de alguns grupos do campo das profissões e mostrar que os problemas do trabalho e do sentido da vida profissional concernem a todo mundo.

Dubar (2001) também trabalha com a noção de profissionalidade, construída a partir da articulação de três processos, que envolvem a formação inicial e contínua das competências, sua codificação nos sistemas de emprego e o reconhecimento, que resulta do jogo das relações profissionais. A profissão de um indivíduo seria resultado da articulação entre um conhecimento adquirido e o reconhecimento social de sua utilidade. O reconhecimento social da utilidade da atividade se dá através da inserção no mercado de trabalho, em decorrência do conhecimento adquirido (Franzoi, 2003). O não reconhecimento acontece quando a qualificação do trabalhador não passa por canais institucionais que a legitimam.

Dubar (2001) propõe a denominação "formas de identidade", refletindo o duplo sentido do termo identidade como definição pessoal de si e como definição de si pelos outros. A questão do trabalho, de seu lugar na sociedade e do sentido que lhe é atribuído parece constituir a dimensão central das identidades. Uma reflexão sobre a questão das identidades profissionais torna necessário distinguir, ao menos, duas formas de identidades relacionadas às situações de emprego e trabalho. Uma seria a identidade de pertencimento, inscrita na continuidade de uma forma histórica preexistente que fornece a identificação principal; a outra, uma identidade incerta, resultante de rupturas, que implicam novas identificações.

As identidades constituem modelos culturais de organização, formas de enfrentar o poder, que dependem tanto do trabalho, dos valores, crenças e representações empregados na atividade profissional, como dos espaços ocupados fora do trabalho. Segundo Paiva (2000), estudos empíricos realizados pelos estudiosos da sociologia do trabalho constatam forte heterogeneidade nos discursos de trabalho entre trabalhadores que compartilham uma situação de trabalho comum e, inclusive, entre os que integram a mesma categoria profissional.

O entendimento de que a identidade é tanto social como pessoal define a subjetividade como questão a ser considerada na análise dos fatos sociais contemporâneos. Os campos objetivos do social devem se articular com as 
esferas das experiências subjetivas, no sentido de manter uma certa unidade reflexiva e narrativa de si mesmo. O trabalho parece seguir como processo central, pelo qual se constituem formas de reconhecimento de si, maneiras de ser ator, de pertencer. Assim, é questionada a visão determinista que relaciona, de forma estreita, situação de trabalho e formas de identificação dos trabalhadores. A situação, considerada apenas no sentido objetivo, não seria suficiente para compreender as identidades no trabalho. A identidade não é somente construída para os outros; ela é também, permanentemente, reconstruída para o próprio indivíduo ao longo de toda a vida.

O conceito de identidade, em uma perspectiva sociológica, é um processo de reconstrução ao longo da vida, que associa identidade e socialização, na medida em que a identidade é produto de sucessivas socializações (Franzoi, 2003). Seguindo essa conceituação, a noção de trajetória refere-se à articulação entre as estratégias individuais e ao marco histórico social em que se situam os sujeitos. As heranças e as posições de classe fazem parte desse contexto, que imprime sua marca nas trajetórias continuamente reconstruídas pelo sujeito. A compreensão do mundo social só pode emergir na particularidade de uma realidade empírica, historicamente situada e datada.

\section{O grupo profissional estudado}

O setor terciário agrega, à criação de novas categorias profissionais, a característica de grande heterogeneidade, tanto em relação aos seus processos técnicos, formas de organização da produção e do trabalho, quanto em relação aos trabalhadores inseridos no setor, no que diz respeito à qualificação, formação, remuneração e estabilidade. Nesse sentido, percebeu-se a necessidade de definir o grupo ocupacional a ser analisado, a partir da compreensão da complexidade da realidade social, da diversidade de trajetórias profissionais, processos de trabalho e formas de organização do trabalho nesses espaços organizacionais.

No caso dos trabalhadores administrativos, Dubar (2001) aponta o pertencimento à organização como característica importante. Essa noção de pertencimento seria responsável pela origem de uma nova forma de identidade, denominada 'identidade de organização', que implica forte mobilização subjetiva, esperanças de desenvolvimento de carreira e alta dependência aos modos de gestão da organização. No entender de White (1942), esses trabalhadores seriam os "homens organizacionais" (apud Dubar, 2001, p. 7).

Na tentativa de identificar uma tipologia do setor terciário, considerando-se as características dos trabalhadores, são encontrados três grandes grupos de atividades. A saúde aparece inserida no grupo do ensino e da pesquisa, grupo que apresenta características particulares: importante 
proporção de quadros de profissões intelectuais e intermediárias e de trabalhadores administrativos; assalariamento generalizado; remuneração elevada; feminização superior à média; pertencimento a grandes empresas ou organizações; forte estabilidade; taxa de participação na formação continuada elevada e difusão do trabalho em tempo parcial.

Esse grupo se subdivide em duas partes. A primeira é composta pelas atividades denominadas socioculturais que, mesmo beneficiando-se do progresso técnico, é, primordialmente, fundada sobre uma relação pessoal, orientada para o diagnóstico, o aconselhamento, a formação e a atenção. A outra parte, composta por atividades denominadas técnico-administrativas, apresenta forte conteúdo informacional, relacionada a uma característica mais abstrata dos serviços. As atividades desempenhadas por este grupo de trabalhadores seriam as mais atingidas pela racionalização e informatização, que acabam por afetar sua produtividade.

O subgrupo denominado técnico-administrativo10 foi o mais atingido pela racionalização das atividades, sua informatização e automatização. Esse movimento acaba por ocasionar a diminuição dos empregos menos qualificados e o aumento das qualificações mais amplas. Exige-se uma polivalência maior dos trabalhadores e as questões prioritárias tendem a se deslocar da função administrativa para a função comercial e relacional que, em função do aumento das exigências e intensificação da concorrência, passa a demandar uma abordagem mais técnica e personalizada (Deluiz, 1995).

De acordo com os dados da pesquisa Assistência médica sanitária, realizada pelo IBGE em 2002, o "pessoal administrativo" representa $25 \%$ dos postos de trabalho ocupados nos estabelecimentos de saúde. No entanto, apesar de os trabalhadores administrativos nas unidades de saúde representarem um contingente quantitativamente importante entre os trabalhadores dessas organizações, ainda é raro o entendimento de que essas áreas conformam importantes subsistemas organizacionais do setor, tornando-se fundamental compreender esses trabalhadores como sujeitos construtores do sistema público de saúde. Os trabalhadores administrativos não são profissionais exclusivos ou especialistas de um setor específico, já que em suas trajetórias de trabalho podem passar por todos os setores de apoio aos serviços, como recursos humanos, orçamento, almoxarifado, registros e informações, farmácia, recepção.

Apesar de as entrevistas terem sido realizadas em apenas duas unidades de saúde - um posto e um hospital - vários dos entrevistados já haviam passado por outras unidades e pelo nível central, e essa trajetória acabou sendo recuperada nos depoimentos. Foram entrevistados 18 trabalhadores no período de um ano, entre $2003 \mathrm{e}$ 2004. No primeiro ano foram aplicados questionários e foram realizadas três entrevistas com chefias de setores administrativos. Em 2004 foram realizadas entrevistas de aprofundamento com parte dos entrevistados em 2003, além de novas entrevistas. 
Todos os trabalhadores administrativos entrevistados eram servidores públicos municipais ou federais, recebiam entre quatro e seis salários mínimos e trabalhavam numa carga horária entre 20 e 40 horas semanais, sendo o regime de trabalho de diaristas e plantonistas.

Foram selecionados trabalhadores que atuassem em diferentes setores administrativos, que possuíssem vínculos diferenciados (federal e municipal) e que tivessem tempos distintos de atuação no cargo. Os entrevistados receberam nomes fictícios, os que iniciam com a letra M são servidores municipais e os com letra F, federais. A análise do material empírico foi circunscrita aos relatos de 18 trabalhadores técnico-administrativos, que conformaram o foco do estudo. O estudo do grupo profissional escolhido foi realizado através da análise das trajetórias ocupacionais, considerando a inserção inicial dos trabalhadores na área administrativa, a situação atual de trabalho e as expectativas profissionais.

\section{A construção dos 'modos de ser': trabalhador administrativo}

O momento de ingresso no serviço público revela expectativas diferenciadas para os trabalhadores administrativos. A maior parte dos mais antigos inseriram-se no serviço público aproveitando a oportunidade existente, na época, de serem contratados para algumas vagas. Nesse caso, o trabalho se encontra fortemente marcado pela sua dimensão de emprego, como apontado no depoimento de Marisa.

Marisa é copeira, função que nunca exerceu, tem 50 anos de idade e 27 anos de serviço público. Foi contratada como copeira, pois os demais cargos já haviam sido preenchidos e na época "o importante era arrumar um emprego".

“(...) surgiu a oportunidade, na época a facilidade do emprego (...). Era muito mais fácil do que hoje, as pessoas entravam. Quando eu cheguei lá não tinha mais nada, os melhores cargos já tinham sido preenchidos. Eu fui, mas falei: ‘Eu não vou ficar na copa, eu não vou servir café para ninguém, porque eu só sirvo café na minha casa', e soou assim meio rebelde. Tanto que eu logo peguei a parte de pessoal" (Marisa).

Outra parte dos entrevistados, com menor tempo de serviço, ao fazer o concurso para agente administrativo, acreditava ser possível utilizar seus conhecimentos na realização das atividades profissionais e, possivelmente, adquirir reconhecimento através de um trabalho de maior responsabilidade. Esse é o caso de Maria, 43 anos, agente administrativo do município desde 2002. Quando ingressou no posto de saúde, foi trabalhar no almoxarifado, e, há um ano, se tornou chefe do setor. É economista e está fazendo pós- 
graduação na sua área de formação profissional. Nunca fez cursos relacionados ao setor administrativo, mas está inscrita em um oferecido pela Fundação João Goulart, conveniada da Secretaria Municipal de Saúde (SMS-RJ), aguardando, em uma grande lista de espera, ser chamada.

Maria estava desempregada e no meio do curso de economia de uma universidade pública quando prestou concurso para o município do Rio.

“Eu fiquei um tempo desempregada, comecei a estudar. Graças a Deus consegui universidade federal e pude continuar estudando, aí eu fiz o concurso pra Niterói, para a Companhia de Limpeza de Niterói e surgiu o concurso aqui, que o salário era melhor. Então foi por isso que eu fiz... Sabia que o cargo era agente administrativo, nível de segundo grau, mas eu não sabia onde ia parar. Eu achava que vir pra cá poderia ser uma escada, uma ponte, não sei. Pensei assim: de repente, eu trabalhando aqui e as pessoas vendo meu trabalho, haveria essa ponte de eu ser chamada para atuar cursando economia" (Maria).

Parte dos trabalhadores entrevistados iniciou a vida profissional antes de concluir o curso de nível superior, e outra parte prestou concurso para um cargo de nível médio já possuindo essa titulação, como é o caso de Marcelo, que tornou-se funcionário público em busca de estabilidade. Ele tem 30 anos e, há três, prestou concurso para o município do Rio de Janeiro, indo trabalhar em um hospital da zona Sul da cidade. O concurso foi realizado pela Secretaria de Administração do município e, quando ele se apresentou, já estava definida sua unidade de lotação. Marcelo fez direito e já advogava quando ingressou na saúde como agente administrativo. No entanto, para todos os entrevistados, tornar-se agente administrativo não é algo associado à natureza da atividade a ser desenvolvida, não se configura numa situação social de importância privilegiada. O fato de não exigir uma formação profissional específica para o ingresso na ocupação fragiliza a construção da identidade profissional desses trabalhadores.

“O último concurso que teve foi para nível de segundo grau, apesar de eu ter até nível superior e minha formação ser em direito, eu sou advogado também... Mas aqui é só segundo grau, e a opção foi só tentar uma estabilidade, alguma coisa que me garanta" (Marcelo).

Confirmando os achados de Franzoi (2003), percebe-se que parte dos trabalhadores entrevistados busca a profissão desejada no plano das iniciativas de formação profissional, mas não encontra condições objetivas favoráveis de concretizar essa formação no plano da inserção no mercado de trabalho. Esses trabalhadores possuem alguma referência profissional, mas os projetos de trabalho desenhados encontram pouca consonância nas suas tra- 
jetórias profissionais. As tentativas de tornarem-se sujeitos, de construírem seus projetos de vida, de alcançarem identidade social reconhecida passam por caminhos distantes do cargo de agente administrativo. As tentativas de parte dos trabalhadores entrevistados de organizar sua experiência e alcançar reconhecimento distanciam-se daquilo que fazem nas organizações de saúde.

Quase todos os trabalhadores entrevistados transitam pelos diversos setores que compõem a área, conformando os muitos trabalhos administrativos. Esses percursos ocupacionais podem expressar uma busca de identidade profissional. No entanto, da forma como são experimentados, tais percursos, relacionados com as formas de (des)organização do trabalho, parecem dificultar a criação do sentido do trabalho. Assim, dentro ou fora da unidade, buscam construir e ampliar espaços de expressão de si, como é o caso de Felipe que veio para o Rio de Janeiro fazer faculdade e possui outras áreas de interesse, atuando com música e teatro. Para esse trabalhador:

“O administrativo hoje está aqui, amanhã está no computador, no benefício, tomando conta da lavanderia, enfim, tudo. É tudo, embora não tenha que ter especialização, adquire a qualificação na prática, mas nada impede que numa mudança de direção isso mude" (Felipe).

As perspectivas profissionais encontram-se relacionadas ao momento atual de trabalho, sendo influenciadas pelas possibilidades de crescimento e aprendizado vislumbrados ou não no espaço organizacional e no sistema de saúde em que estão inseridos. Felipe diz que não espera mais nada. Considera difícil ascender no próprio trabalho: “dentro da estrutura atual, não tenho para onde ir, estou no topo. E acho que a área de administração nos serviços de saúde não tem aplicação fora da área da saúde" (Felipe).

As expectativas também podem ser associadas com a titulação dos trabalhadores. Aqueles entrevistados que possuem o nível superior completo guardam esperanças de ainda atuar nas suas áreas profissionais, seja prestando novos concursos seja aguardando a aposentadoria para exercer sua profissão.

Maria segue buscando se aperfeiçoar na profissão. Atualmente, cursa pós-graduação na área de economia, com o propósito de passar em outro concurso público e trabalhar na sua área.

“Eu fiz uma pós porque eu queria me aprimorar dentro da economia para fazer alguma coisa... Depois que eu vim para cá, estacionei. Onde eu estou eu não vou para lugar nenhum, o que eu quero mesmo é trabalhar na minha área, então eu fiz a pós, visando a concursos dentro da minha área, é para isso que eu estou atenta agora" (Maria). 
A compreensão da trajetória de trabalho dos agentes administrativos aponta para a questão da dificuldade de construção de um projeto de trabalho. No entanto, cabe sinalizar que os trabalhadores não se sentem confortáveis com a indefinição de seus projetos profissionais. Configura-se uma tensão permanente relacionada ao trabalho, que possui centralidade na consciência dos trabalhadores, o que pode ser verificado quando comparam o trabalho administrativo ao de outras profissões e quando buscam as possibilidades de o trabalho significar fonte de realização.

\footnotetext{
“Você não tem profissão, você tem uma ocupação, você não é um profissional. Isso é fato. Às vezes, eu falo assim: 'Eu trabalho no posto de saúde', 'Ah, você é médico?', 'Não, não sou médico, trabalho na administração'"' (Felipe).
}

Ser agente administrativo não favorece a construção de uma identidade profissional. O questionamento acerca do que são profissionalmente gera um certo desconforto e leva, na maioria dos casos, a uma associação mais forte com o fato de serem, antes de tudo, funcionários públicos.

\section{Considerações finais}

Assim como outras pesquisas sociológicas (Dubar e Tripier, 1998; Franzoi, 2003), constatou-se, entre os trabalhadores administrativos, uma grande diversificação de formas de emprego, percursos profissionais e dinâmicas de identidade.

Foi possível verificar que as transformações do mercado de trabalho sinalizam para uma revisão dos valores relativos ao trabalho. Não cabe falar do fim do trabalho, mas é necessário relativizar a associação entre trabalho e emprego, este deve ser entendido como uma dimensão do trabalho, assim como a formação profissional deve ser compreendida como uma dimensão da qualificação.

Foi reconhecida a necessidade de vincular as análises sobre o cotidiano de trabalho àquelas sobre o mercado de trabalho. Esse é o movimento teóricometodológico mais recente da sociologia do trabalho. O estudo dessas relações se torna um objeto específico da sociologia e encontra-se no centro dos debates sobre o futuro do trabalho que envolve a sociedade. Os resultados encontrados no trabalho de campo guardam semelhança com os achados de pesquisas citados por Gorz (2004). Esses estudos constatam uma desafeição à carreira e a possibilidade de atuação em atividades múltiplas e em tempo parcial. A relação com o trabalho distende-se porque a vida está em outro lugar, especialmente nas atividades não remuneradas, mas consideradas socialmente úteis. Esse autor afirma que o direito ao trabalho é reivindicado 
como um direito político, por isso o problema e sua solução são, antes de tudo, políticos, localizam-se na definição de novos direitos, novas liberdades, novos arranjos do espaço urbano.

Entretanto, esta mudança cultural continuará sendo assunto pessoal, privado, enquanto não for traduzido por uma nova organização do espaço social que permita a cada um expressar-se em novos modos de agir e de viver em sociedade.

A compreensão da trajetória de trabalho dos agentes administrativos aponta para a questão da dificuldade de construção de um projeto de trabalho. A análise do material empírico aproxima-se dos estudos realizados por Bauman (2001), quando identifica a crescente dificuldade de associar trabalho como um eixo central para definição de identidades e projetos de vida, quando o trabalhador se aproxima da imagem de um executante qualquer e o trabalho vira emprego.

Este estudo, assim como outras tentativas recentes de síntese relacionadas à temática do trabalho, das organizações produtivas ou das formas de atividade humana, acentua as incertezas da sociedade atual. Nesse sentido, Dubar e Tripier (1998) não acreditam num reposicionamento de novas teorias sobre as antigas. Apontam a sociologia como uma disciplina compreensiva, sujeita a permanentes conflitos e incessantes confrontações de pontos de vista. Os pesquisadores das profissões, do trabalho ou das organizações devem ser convocados a articular diferentes paradigmas, combinar conceitos, métodos e técnicas de diferentes tradições teóricas e de disciplinas próximas.

Dar coerência às trajetórias subjetivas, aos mundos do trabalho e às concepções de saber profissional impulsionam a lógica relacionada ao sentido dado ao trabalho, a antecipação do percurso profissional e suas crenças dos saberes úteis. São lógicas de identidade no campo profissional, e que também constituem a dinâmica profissional, quer dizer, os percursos típicos de emprego-qualificação, ligados às crenças subjetivas sobre o trabalho.

O sentido de percurso ocupacional constitui uma dimensão-chave para compreender as lógicas de ação e também da diferenciação das formas de identidade. Assim, as diferentes formas de trajetórias valorizadas pelos trabalhadores associam-se às tentativas de construção de suas formas de identidade em busca de reconhecimento.

A situação de trabalho, considerada apenas no sentido objetivo, não parece suficiente para compreender a construção das formas de identidade. A identidade não é somente construída para os outros; é também, permanentemente, reconstruída para o próprio indivíduo ao longo de toda a vida. Esse entendimento permite compreender os percursos ocupacionais e formativos dos trabalhadores administrativos pelos setores que compõem a área, diferentes unidades de saúde e profissões. 
A construção das formas de identidade do trabalhador administrativo deve ser relacionada com algumas variáveis como vínculo, tempo de serviço e formação profissional. Constatou-se que a construção de uma forma de identidade mais estável relaciona-se com a possibilidade de delineamento de um percurso profissional, ou seja, os trabalhadores que conseguem traçar sua história de trabalho sobre determinada temática percebem-se como sujeitos, com capacidade de construir, ao longo da vida, relações de reconhecimento.

Mesmo que não consiga relacionar a formação profissional com a ocupação exercida, o trabalhador segue buscando profissionalizar-se, num esforço de alcançar identidade e reconhecimento. Na verdade, os trabalhadores reivindicam uma classificação que parta de seus atributos, e não do posto ocupado. Como construir processos de gestão do trabalho que englobem não apenas o tempo de formação formalizado no diploma, ou exigido para a ocupação do cargo, mas também as qualificações tácitas? Como não transformar esse processo numa negociação individualizada?

As conversas sobre a formação profissional, sobre o saber profissional foram significativas. Ainda que alguns questionem a possibilidade de seguir estudando - "estudar para quê?", "não traz nada" -, a maior parte dos trabalhadores segue buscando uma qualificação profissional que, embora não possa ser utilizada na situação atual de trabalho, aparece como importante na conformação de suas identidades profissionais. Outros pensam nas possibilidades de assumir responsabilidades e de cooperar com uma expectativa vaga de crescer na organização. Mais do que a atividade de trabalho desenvolvida, a concepção de cada um sobre a qualificação profissional, os saberes profissionais, os modos de aquisição do aprendizado, sua utilidade, constitui um dos eixos das definições de si mesmo.

Aponta-se para a necessidade de maior aproximação sociológica aos grupos profissionais, que levem em conta a dinâmica social das formas profissionais, diversificando as abordagens anteriores, no sentido de relacionar as questões do saber, da prática com a noção de legitimidade simbólica.

Buscou-se romper com a tentativa de exclusão de alguns grupos do campo das profissões e mostrar que os problemas do trabalho e do sentido da vida profissional concernem a todo mundo. Espera-se, dessa forma, contribuir com a dinâmica de um campo de pesquisa central e em expansão. 


\section{Notas}

1 Pesquisadora do Laboratório do Trabalho e da Educação Profissional em Saúde da Escola Politécnica de Saúde Joaquim Venâncio, Fundação Oswaldo Cruz (EPSJV/Fiocruz), Rio de Janeiro, Brasil. Doutora em Saúde Coletiva pelo Instituto de Medicina Social da Universidade Estadual do Rio de Janeiro (IMS/Uerj). <monicavi@fiocruz.br>

2 Nesse setor está localizada a prestação de serviços e, portanto, a área da saúde.

3 Há um dissenso acadêmico em torno da questão da qualificação devido a diferentes concepções do termo. Esse conceito foi analisado a partir de abordagens diferenciadas, que podem ser sintetizadas em duas visões da qualificação: uma denominada essencialista ou substancialista e outra, relativista. A primeira visão não leva em conta a dinâmica histórica, partindo da qualidade e da complexidade das tarefas para chegar aos atributos necessários dos trabalhadores, ou seja, compreende a qualificação a partir das características objetivas das rotinas de trabalho ou de sua relação com a possibilidade de maior ou menor autonomia. A visão relativista insere-se numa perspectiva multidimensional, que amplia o entendimento do termo, aproximando-o da concepção de um processo social (Tartuce, 2002).

4 A lógica da competência se desenvolveu quase que simultaneamente nas organizações de trabalho e em certos segmentos do sistema educativo nos anos 80, relacionada à busca de maior contribuição dos trabalhadores à competitividade da organização. Nessa fase, a formação continuada na empresa tornou-se uma questão estratégica, possibilitando diversas inovações a partir de uma relação mais estreita entre transformações na organização do trabalho e na gestão. As recomendações da competência como saber fazer e saber ser já existiam nos anos 50 no que diz respeito à formação de gerentes.

5 Na Inglaterra e nos Estados Unidos, a sociologia das profissões existe como 'subdisciplina' com suas teorias e controvérsias próprias. A razão disso é que, nesses países, a legislação distingue as atividades em que seus membros possuem direitos específicos das ocupações em que os membros podem apenas se sindicalizar. Segundo Dubar e Tripier (1998), existe um certo consenso sobre uma definição de profissão que remonta a um artigo de Flexner (1915), que define alguns traços profissionais comuns a todas as profissões: tratam de operações intelectuais associadas a grandes responsabilidades individuais; seus materiais de base são provenientes da ciência e de um saber teórico; comportam aplicações práticas e úteis e são transmitidos por um ensino formalizado; as profissões tendem à autoorganização em associações e seus membros possuem uma motivação altruísta.

6 Flexner (1915) elege uma escala de atributos para conceituar o profissionalismo. Ver Moore (1970).

7 Um estudioso do tema, Abbott (1988), analisa que os teóricos da área percebem a ascensão das profissões por vias distintas. Para alguns sociólogos trata-se de uma questão do conhecimento verificado por meio de uma prática triunfante; para outros, representa uma crônica sobre a obtenção de um monopólio (saber, mercado). Moore (1970) destaca, como traços distintivos das profissões, a vocação - no sentido de um 'chamamento' - e a identificação entre os pares.

8 Para um melhor entendimento, ver Larson (1977), especialmente a primeira parte do livro, quando a autora analisa a organização dos mercados profissionais. 
9 Segundo Dubar e Tripier (1998), não existe na Franca oposição entre profissão e ocupação, sendo encontrados três universos de significados para o termo profissão: é algo que se anuncia publicamente, relacionada a crenças político-religiosas; é o trabalho realizado e que permite viver graças a um salário; e pode ser o conjunto de pessoas que exercem o mesmo ofício, mais próximo do termo grupo profissional (mesmo status profissional).

10 Os trabalhadores administrativos estão sendo considerados como aqueles responsáveis por uma série de atividades integradas e interdependentes, destinadas a permitir que certa combinação de meios possa gerar uma produção de bens ou serviços econômica e socialmente úteis (Acktouf, 1996).

\section{Referências}

АВвОTТ, Andrew. The system of professions: an essay on the division of expert labor. Chicago: The Chicago Press, 1988.

ACKTOUF, Omar. A administração entre a tradição e a renovação. São Paulo: Atlas, 1996.

ANTUNES, Ricardo. Os sentidos do trabalho: ensaio sobre a afirmação e a negação do trabalho. São Paulo: Boitempo Editorial, 2000.

BAUMAN, Zygmunt. O mal-estar da pósmodernidade. Rio de Janeiro: Jorge Zahar, 2001.

BOURDIEU, Pierre. Razões práticas: sobre a teoria da ação. 5.ed. Campinas: Papirus, 2004.

BRAVERMAN, Harry. Trabalho e capital monopolista. 3.ed. Rio de Janeiro: Guanabara, 1987.

CASTEL, Robert. As metamorfoses da questão social: uma crônica do salário. Petrópolis: Vozes, 1998.

CASTRO, Nadya Guimarães. Organização do trabalho, qualificação e controle na indústria moderna. In: Trabalho e educação - Coletânea CBE. 2. ed. Campinas: Papirus, 1994. p. 69-83.

CASTRO, Nadya Guimarães; LEITE, Marcia. A sociologia do trabalho industrial no Brasil: desafios e interpretações. Revista Brasileira de Informação Bibliográfica em Ciências Sociais. Rio de Janeiro, n. 37, p. 39-59, 1 sem., 1994.
DELUIZ, Neise. Formação do trabalhador: produtividade e cidadania. Rio de Janeiro: Shape Editora, 2001.

DUBAR, Claude. El trabajo y las identidades profesionales y personales. Trayectorias Ocupacionales y Mercado de Trabajo. Revista Latinoamericana de Estudios del Trabajo, Buenos Aires, ano 7, n. 13, p. 5-15, 2001.

DUBAR, Claude.; TRIPIER, Pierre. Sociologie des professions. Armand Colin, Paris: Editions Armand Colin, 1998.

FARTES, Vera Lúcia Bueno. Trajetórias educacionais e profissionais de trabalhadores na indústria petroquímica brasileira: um processo multidimensional de aquisição de qualificação. Trayectorias Ocupacionales y Mercado de Trabajo. Revista Latinoamericana de Estudios del Trabajo, Buenos Aires, ano 7, n. 13, p. 53 - 73, 2001.

FRANZOI, Naira. Da Profissão como profissão de fé ao "mercado em constante mutação": trajetórias e profissionalização dos alunos do Plano Estadual de Qualificação do Rio Grande do Sul (PEQ-RS). Tese de doutorado em Educação. Faculdade de Educação da Universidade Estadual de Campinas, São Paulo, 2003.

FREIDSON, Eliot. La profesion médica: un estudio de la sociología del conocimiento aplicado. Barcelona: Ediciones Península, 1978. 
GOODE, William. The theoretical limits of profissionalization. In: ETZIONI, Amitai (Org.). The semi-professions and their organization. Londres: The Free Press, 1969, p. 266-313.

GORZ, André. Adeus ao proletariado: para além do socialismo. Rio de Janeiro: Forense, 1982.

Misérias do presente, riqueza do possivel. São Paulo: Annablume, 2004.

HARVEY, David. Condição pós-moderna. 6. ed. São Paulo: Loyola, 1996.

HONNETH, Axel. Luta por reconhecimento: a gramática moral dos conflitos sociais. Tradução Luiz Repa. São Paulo: Editora 34, 2003.

INSTITUTO BRASILEIRO DE GEOGRAFIA E ESTATÍSTICA. Estatísticas da Saúde: Assistência Médica Sanitária 2002. Rio de Janeiro: IBGE, 2002.

LARSON, Magaly. Sarfati. The rise of profissionalism: a sociological analysis. Los Angeles: University of California Press, 1977.

LEITE, Márcia; SILVA, Roque Aparecido. A sociologia do trabalho frente à reestruturação produtiva: uma discussão teórica. Revista Brasileira de Informação Bibliográfica em Ciências Sociais, Rio de Janeiro, n. 42, p. 41-57, 2 sem. 1996.

MOORE, William. The professions: roles and rules. Nova York: Russel Sage Foundation, 1970.
OFFE, Claus. Capitalismo desorganizado. São Paulo, Brasiliense, 2.ed.1994.

PAIVA, Vanilda. Novos padrões econômicos e demanda de qualificação e competências. Reestructuración y Trabajo en la Producción Agroalimentaria. Revista latinoamericana de Estúdios del Trabajo, Buenos Aires, ano 6, n. 12, p. 139-152, 2000.

RISEK, Cibele. Saliba. Interrogações a um campo teórico em crise. Tempo Social Revista de Sociologia da USP, São Paulo, v. 6, n. 1-2, p. 147-179, 1994.

SENNET, Richard. A corrosão do caráter: conseqüencias pessoais do trabalho no novo capitalismo. Rio de Janeiro: Record, 1999.

STARR, Paul. The social transformation of American medicine. Nova York: Basic Books, 1982.

TARTUCE, Gisela Lobo Pereira. O que há de novo no debate da "qualificação do trabalho"?. Reflexões sobre o conceito com base nas obras de Georges Friedmann e Pierre Naville. Dissertação de mestrado em Sociologia. Faculdade de Filosofia, Letras e Ciências Humanas da Universidade de São Paulo, São Paulo, 2002.

Recebido em 03/02/2006

Aprovado em 02/06/2007 